\title{
Friction stir welding of high-strength steel type TRIP 700
}

\author{
P. Zifčák*, P. Blažiček, R. Stancel \\ Welding Research Institute - Industrial Institute of SR, Račianska 71, 83259 Bratislava, Slovak Republic
}

Received 19 September 2014, received in revised form 27 July 2015, accepted 27 April 2016

\begin{abstract}
This study presents the results of welding high-strength steel type TRIP 700 with $1.56 \mathrm{~mm}$ in thickness welded by friction stir welding (FSW) technology. Welding was performed by application of tungsten carbide (WC) welding tool at constant spindle revolution $400 \mathrm{rev} \mathrm{min}^{-1}$ on zinc coated and uncoated steel sheets. Welding results have revealed the occurrence of inhomogeneities, which were observed to more or less extent on all welds, regardless the welding parameters. However, the certain improvement was observed on uncoated sheets. This study analyses the reason for defects formation and degradation of welding tools owing to welding parameters. The results from weld defects analysis were an incentive for the design of a modified welding tool geometry, which was subsequently used in the new experiments. The results of new experiments were positive and are presented within this work. Mechanism of WC tools damage was considered together with their life. The microstructure of welded joints is documented in this study, together with hardness profiles in dependence on selected welding parameters.
\end{abstract}

Key w ord s: FSW, high-strength steel, lifetime of WC tool, microstructure

\section{Introduction}

Development of high-strength steels or progressive steels used in the car industry is stimulated by the need to reduce the fuel consumption and also the material and energy spent in manufacture. This aim is met by application of high-strength materials, allowing to use lower material wall thickness. Application of thinner materials results in vehicle weight reduction but also in life prolongation, however, higher strength and reliability of components must be guaranteed [1].

The TRIP steel (TRansformation Induced Plasticity steel) developed for the needs of car industry belongs to the group of high-strength materials which allows meeting the mentioned criteria. These steels are typical with a high formability, strength and resistance against thinning at forming. The microstructural base of TRIP steels consists of a ferritic matrix with a certain proportion of residual austenite, bainite and martensite. Transformation of residual austenite to martensite with lath morphology takes place during deformation, which increases the overall strength of steel. Mechanically induced martensite is formed from residual austenite only up to a certain MD temperature. Above this temperature induction of martensite does not occur, but rather austenite deformation. In order to exert this TRIP effect, a minimum proportion of residual austenite $(5-10 \%)$ in the structure is necessary. This is ensured by an increased content of carbon and silicon [2].

Problematic weldability is one of the limitations for a wider application of TRIP steels since there does not yet exist any conventional method permitting to fabricate the weld with properties offered by this steel. The effect of welding causes softening in the heat affected zone and thus reduction of utility properties for which this steel was developed [3, 4].

\section{Experimental}

The high-strength steel type TRIP 700 (TRansformation Induced Plasticity), $1.56 \mathrm{~mm}$ in thickness, was used for welding. Steel surface is hot-dip galvanised by $\mathrm{Zn}$ layer type Z100MB. The average thickness of zinc coated layer was $12 \mu \mathrm{m}$. The chemical composition of

*Corresponding author: tel.: +421 24924 6799; fax: +421 24924 6369; e-mail address: zifcakp@vuz.sk 
Table 1. Chemical composition and mechanical properties of steel type TRIP 700

\begin{tabular}{|c|c|c|c|c|c|c|c|}
\hline \multirow{2}{*}{ Steel type } & \multicolumn{4}{|c|}{ Chemical composition (wt.\%) } & \multicolumn{3}{|c|}{ Mechanical properties } \\
\hline & $\mathrm{C}$ & $\mathrm{Si}+\mathrm{Al}$ & $\mathrm{Mn}$ & $\mathrm{Nb}$ & $R_{\mathrm{e}}(\mathrm{MPa})$ & $R_{\mathrm{m}}(\mathrm{MPa})$ & $A(\%)$ \\
\hline Trip 700 & 0.2 & 1.5 & $1.5-2.2$ & $<0.04$ & 485 & 710 & 34 \\
\hline
\end{tabular}

Table 2. Dimensions of welding tools and welding parameters

\begin{tabular}{|c|c|c|c|c|c|c|}
\hline \multirow{2}{*}{$\begin{array}{l}\text { Zinc surface } \\
\text { coating }\end{array}$} & \multirow{2}{*}{ Exp. No. } & \multirow{2}{*}{ Tool design } & \multicolumn{4}{|c|}{ Welding parameters } \\
\hline & & & $\begin{array}{c}\text { Pin angle } \\
\left({ }^{\circ}\right)\end{array}$ & $\begin{array}{l}\text { Tilt } \\
\left({ }^{\circ}\right)\end{array}$ & $\begin{array}{l}\text { Spindle speed } \\
\left(\text { rev } \min ^{-1}\right)\end{array}$ & $\begin{array}{l}\text { Welding speed } \\
\left(\mathrm{mm} \mathrm{min}^{-1}\right)\end{array}$ \\
\hline \multirow[t]{5}{*}{ Yes } & $\mathrm{P} 1$ & $\mathrm{~A} 1$ & 10 & 3,3 & 400 & 200 \\
\hline & $\mathrm{P} 2$ & $\mathrm{~A} 1$ & 10 & 2,7 & 400 & 200 \\
\hline & P3 & $\mathrm{A} 1$ & 10 & 2 & 400 & 200 \\
\hline & $\mathrm{P} 4$ & B1 & 20 & 2 & 400 & 150 \\
\hline & $\mathrm{P} 5$ & B1 & 20 & 2 & 400 & 200 \\
\hline \multirow[t]{14}{*}{ No } & $1 \mathrm{~N}$ & $\mathrm{~B} 2$ & 20 & 3 & 400 & 150 \\
\hline & $2 \mathrm{~N}$ & $\mathrm{~B} 2$ & 20 & 3 & 400 & 100 \\
\hline & $3 \mathrm{~N}$ & B3 & 20 & 3 & 400 & 200 \\
\hline & $4 \mathrm{~N}$ & B3 & 20 & 3 & 400 & 200 \\
\hline & $5 \mathrm{~N}$ & B3 & 20 & 3 & 400 & 200 \\
\hline & $6 \mathrm{~N}$ & B3 & 20 & 3 & 400 & 250 \\
\hline & $7 \mathrm{~N}$ & B3 & 20 & 3 & 400 & 300 \\
\hline & $8 \mathrm{~N}$ & B3 & 20 & 3 & 400 & 350 \\
\hline & $9 \mathrm{~N}$ & $\mathrm{C} 1$ & 30 & 3 & 400 & 200 \\
\hline & $10 \mathrm{~N}$ & $\mathrm{C} 1$ & 30 & 3 & 400 & 200 \\
\hline & $11 \mathrm{~N}$ & $\mathrm{C} 1$ & 30 & 3 & 400 & 250 \\
\hline & $12 \mathrm{~N}$ & $\mathrm{C} 1$ & 30 & 3 & 400 & 300 \\
\hline & $13 \mathrm{~N}$ & $\mathrm{C} 1$ & 30 & 3 & 400 & 200 \\
\hline & $14 \mathrm{~N}$ & $\mathrm{C} 2$ & 30 & 3 & 400 & 200 \\
\hline
\end{tabular}

this steel together with mechanical properties is given in Table 1.

Welding was performed on a gantry welding equipment type GANTRY FSW-LM-060, with max. $12 \mathrm{t}$ downward force.

Welding was in the case of all experiments performed at the same revolution speed $400\left(\mathrm{rev} \mathrm{min}{ }^{-1}\right)$, where only parameters as welding speed and spindle tilt were altered.

Friction stir welding was performed on butt welded sheets with dimensions $150 \times 350 \times 1.56 \mathrm{~mm}^{3}$. The welding tool was made of tungsten carbide (WC) with dimensions $\varnothing 12 \times \varnothing 5 \mathrm{~mm}^{2}$ (shoulder diameter $\times$ pin diameter in the root).

Microstructural analysis was carried out by light microscope type OLYMPUS 51GX. The observation was performed on a cross section prepared from the selected welded joints approximately in the middle of weld length, i. e. $150 \mathrm{~mm}$ from the start of welding. The specimens for observation were prepared by grinding, mechanical polishing and etching in LaPera etchant (4\% picric acid in ethanol and $1 \% \mathrm{Na} 2 \mathrm{~S} 2 \mathrm{O} 5$ in distilled water. Both these compo- nents are diluted in 1:1 proportion. NITAL is another type of etchant consisting of $4 \%$ nitric acid $\mathrm{HNO}_{3}$ in ethanol.

The hardness of welded joints was measured by Vickers method at $9.05 \mathrm{~N}$ (HV 1) load on hardness tester type Zwick 3212. Hardness was measured on metallographic cross sections of welded joints. Spacing amongst the indents on the base metal and weld metal was $1 \mathrm{~mm}$. In the case of HAZ the spacing amongst the indents was selected to $0.3 \mathrm{~mm}$. 34 measurements were performed on each specimen.

The semi-quantitative analysis and fractographic analysis of tool's fractured surface was performed on electron scanning microscope type JEOL 5800 connected with dispersion analyser type LINK 3.1.

\section{Results}

Welding was performed on steel type TRIP 700 with zinc-coated surface and also with the pickled surface (the $\mathrm{Zn}$ layer was removed). The used welding parameters are summarised in Table 2. 


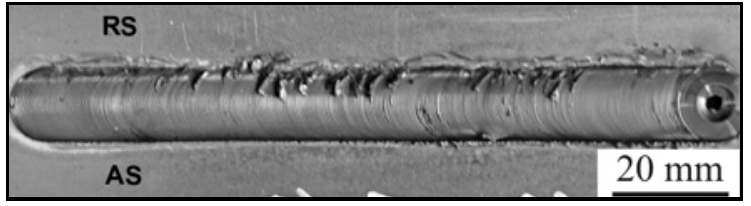

Fig. 1. The best-fabricated weld joint No. P4 welded by parameters: $400 \mathrm{rev} \mathrm{min}^{-1}, 150 \mathrm{~mm} \mathrm{~min}^{-1}$.

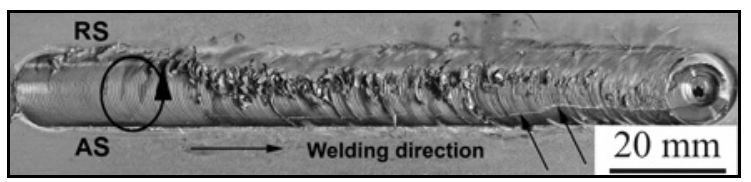

Fig. 2. The worst-fabricated weld joint No. P5 welded by parameters: $400 \mathrm{rev} \mathrm{min}^{-1}, 200 \mathrm{~mm} \mathrm{~min}^{-1}$.

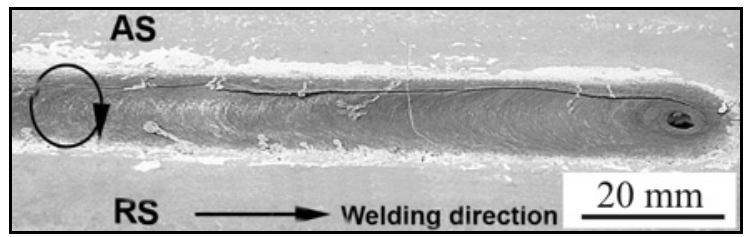

Fig. 3. A detailed view of a crack progressing from the lower side of the weld, located on its advancing side.

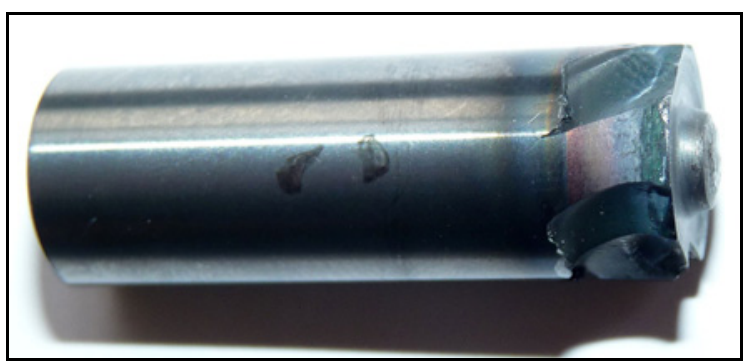

Fig. 4. Tungsten carbide (WC) welding tool after welding about $600 \mathrm{~mm}$ of weld length. The tool does not show any features of shape deformation or changed geometry; it rather shows a peeled off shoulder on its periphery.

\subsection{Welding the zinc-coated sheets of TRIP 700 steel}

Visual inspection oriented to the presence of inhomogeneities either on weld surface or in its root was performed on all welds regardless the welding parameters (Table 2). Cracks initiated from the lower side of weld on its advancing side (Figs. 2, 3) or also in the root zone owing to insufficient root stirring. A more detailed analysis of formed defect is given in the chapter describing welding of uncoated sheets of steel type TRIP 700. Figure 1 shows the best fabricated welded

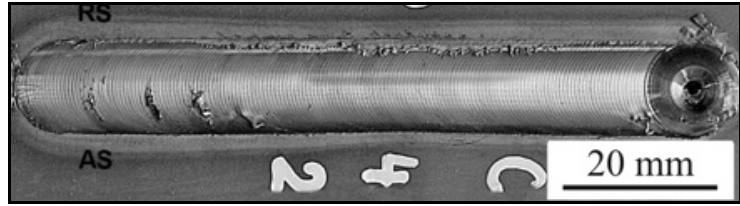

Fig. 5. Welded joint No. 9N welded with parameters: 400 rev $\min ^{-1}, 200 \mathrm{~mm} \mathrm{~min}^{-1}$.

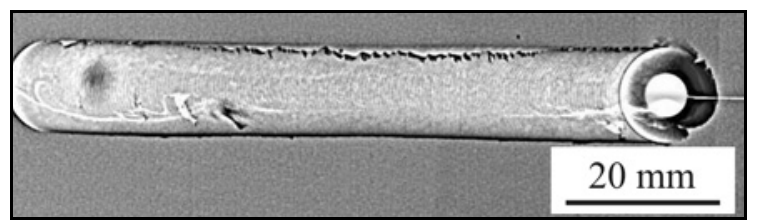

Fig. 6. Radiogram of welded joint No. 9N welded with parameters: $400 \mathrm{rev} \mathrm{min}^{-1}, 200 \mathrm{~mm} \mathrm{~min}^{-1}$.

joint, whereas Fig. 2 shows the worst joint fabricated on zinc-coated sheets.

Regarding the life of WC welding tools, this varied from 600 to $900 \mathrm{~mm}$ of weld length. The life of tools was not terminated due to changed geometry but owing to damage of welding tool in the shoulder zone as shown in Fig. 4.

Besides the mentioned cracks, also metal shavings (filling) were to more or less extent observed on the weld surface, located mostly on the retreating side of the weld (Figs. 1, 2), which can be removed from the surface by grinding paper. This occurrence of metal shavings is attributed to surface coating with a zinc layer which is forced out by plastic strain behind the trailing edge of the tool.

This assumption may also be supported by a white colouring of the metal shavings. The welds fabricated on the sheets without zinc coating were free from occurrence of the mentioned chips.

\subsection{Welding zinc coated sheets of TRIP steel - pickled in the weld zone}

Regarding the previous results, the experimental part of research continued by modification of welded material, namely that the zinc-coated sheets of TRIP steel were again welded. However, the zinc layer in the weld zone was pickled (removed) by use of $10 \% \mathrm{HCl}$ (hydrochloric acid). Pickling time of sheets was $10 \mathrm{~min}$. After pickling, the welded surfaces were cleaned with ethanol.

Results of welding experiments, regardless the welding parameters used, were similar as in the case of welding zinc coated steels. Cracks were again observed from the lower side of welds, though in less extent, localised on the advancing side. In the case of welding parameters No. $6 \mathrm{~N}$ and 9N (Tab. 2, Figs. 5, 


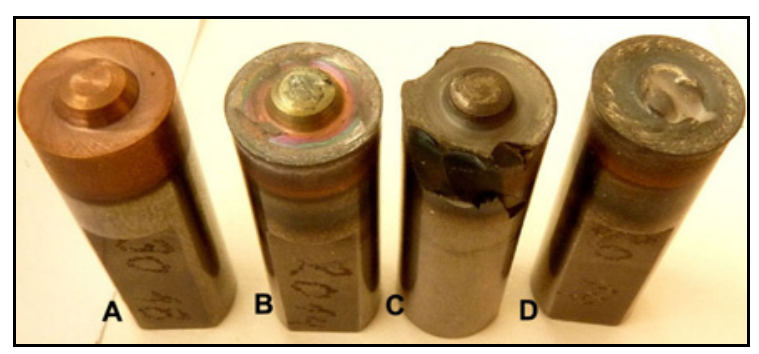

Fig. 7. A view on welding tools prior to and after welding: A - prior to welding; B - after welding, at optimum welding parameters; C, D - after welding at unsuitable welding parameters.

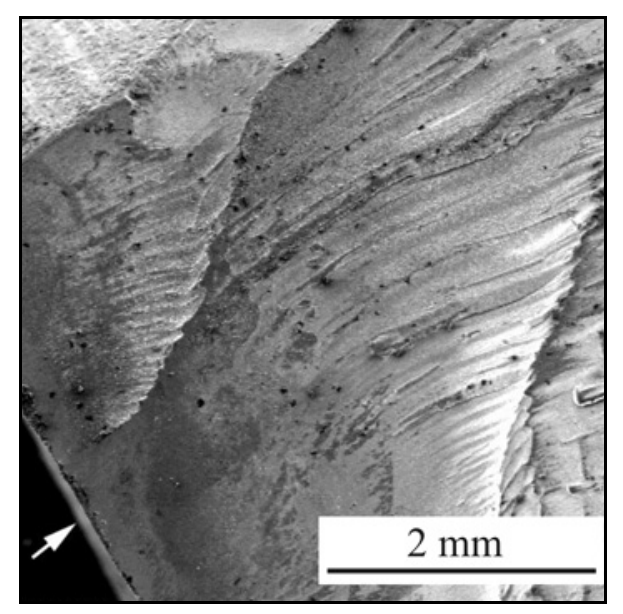

Fig. 8. Overall view on the fractured surface of the welding tool.

6) the central part of overall weld length exerted a homogeneous character from the viewpoint of digital radiography. Moreover, the presence of metal shavings on the weld surface was also eliminated. On weld periphery, the flash was formed, which is a typical accompanying feature of welding. The used welding tools have welded about $1500 \mathrm{~mm}$ length of the weld with the partial wear of the pin, as shown in Fig. 7 .

\subsection{Damage analysis of WC welding tools}

In this part, we were oriented to failure analysis of welding tool used for welding hot dip coated steel type TRIP 700. Overall view on welding tools is shown in Fig. 7. New tool is shown first from the left, which was not used for welding, next is the tool which was not damaged by welding (partially worn on the pin tip), next is the tool with shoulder damaged owing to welding zinc coated sheets, and finally the tool with broken pin owing to unsuitable welding parameters. Welding tools are usually damaged by breaking off the pin since that is the most exposed part of the welding tool. In the case of welding zinc coated sheets, the tool was

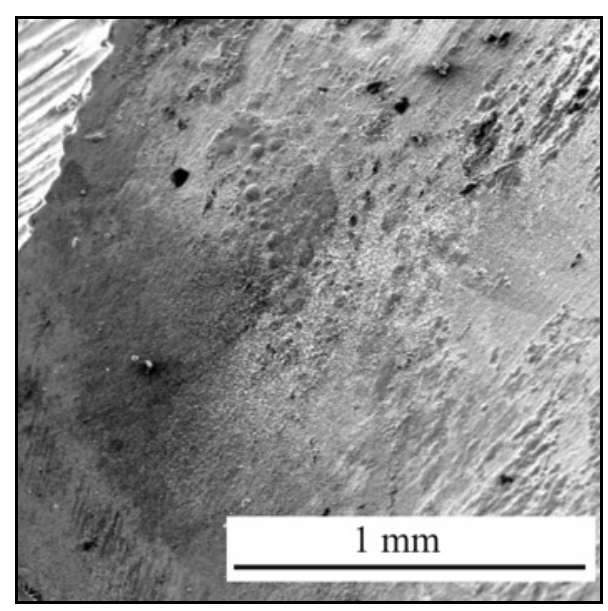

Fig. 9. Detailed view on the smooth part of the fractured surface.

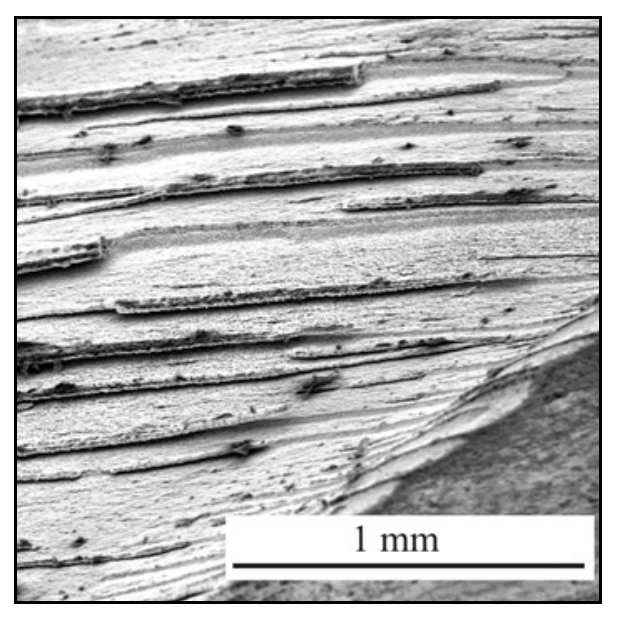

Fig. 10. Detailed view of the stepped part of the fractured surface.

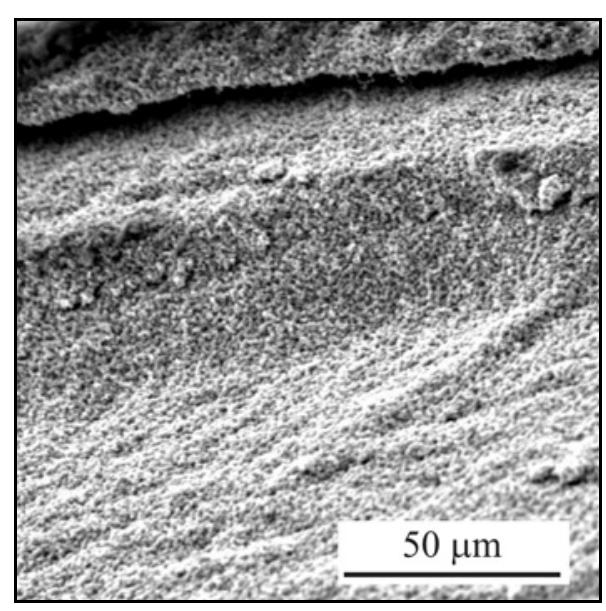

Fig. 11. Detailed view of formed step. 


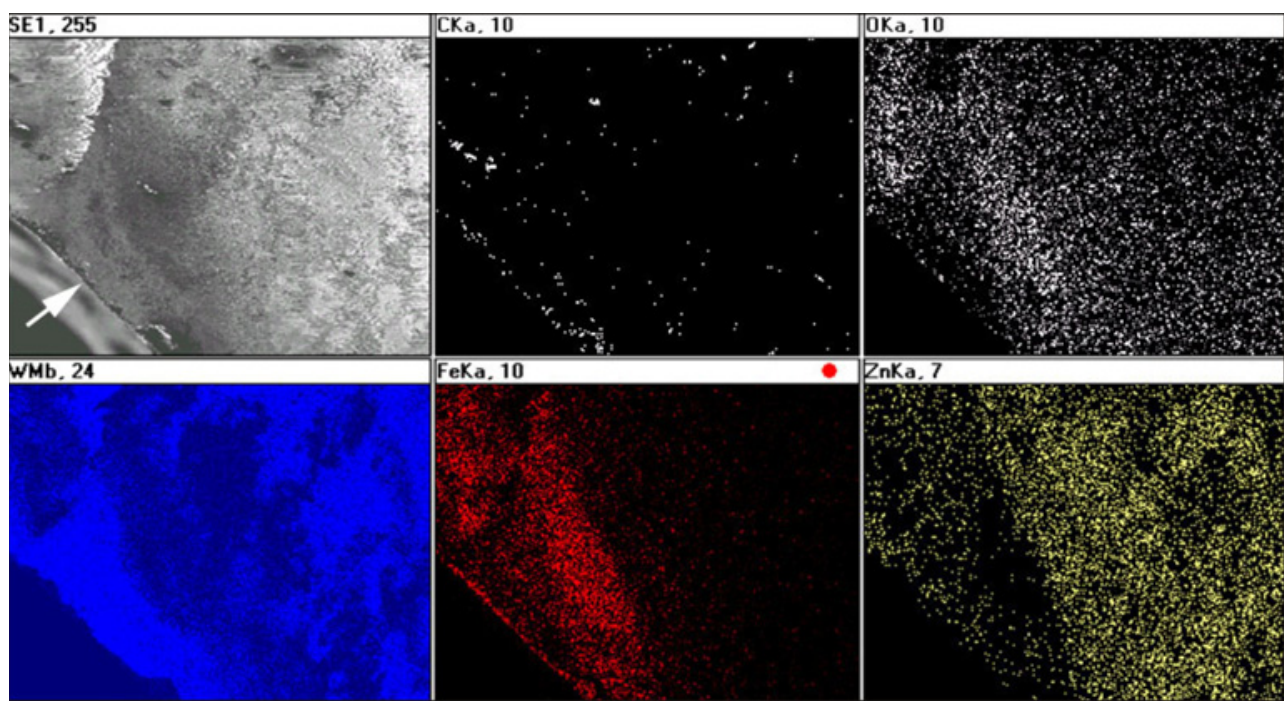

Fig. 12. EDX map analysis of fractured surface shown in Fig. 8.

damaged by breaking off (peeling) of the shoulder on its periphery what is not a current phenomenon. The failure character was analysed from this point of view since our effort is to weld also the zinc coated sheets, what is the requirement of the manufacturer of these materials destined for the car industry. The character of fractured surfaces is documented in a series of figures Fig. 8 to Fig. 11. Overall view of the fractured surface of the tool shoulder is shown in Fig. 8 with a white arrow showing the tool face. The fractured surface in a direction from the tool face is smooth (Fig. 8, detailed view in Fig. 9) and at the end at the point of final rupture the fractured surface is stepped, with eventually regular cascades (Figs. 10, 11). Lamination (shearing off) of material has occurred in this zone due to the effect of shear stresses.

Planar EDX map analysis was carried out on the fractured surface in the location shown in Fig. 8. Planar distribution of elements (Fig. 12) has shown that in the direction from tool face, the surface of the fractured area is covered by a narrow band of iron oxide. The remaining part of the fractured surface is covered by $\mathrm{Zn}$ layer to such extent that it overlaps the matrix composed of WC-Co. Regarding the fact that welding of steels takes place at temperatures higher than $1200^{\circ} \mathrm{C}$, what is temperature considerably exceeding the melting point of $\mathrm{Zn}\left(692^{\circ} \mathrm{C}\right)$, the liquation of liquid $\mathrm{Zn}$ to the material of welding tool (WC-Co) has probably occurred. The liquid phase penetrated along the boundaries of a fine-grained structure formed by sintering of ultra fine-grained WC-Co powder, what resulted in a reduction of its strength, embrittlement and final damage of welding tool thus occurred. This phenomenon is called liquid metal embrittlement. The remaining part of $\mathrm{Zn}$ layer was forced to the trailing edge of tool shoulder, what was manifested by excessive formation of metal shavings (Fig. 2). The worst

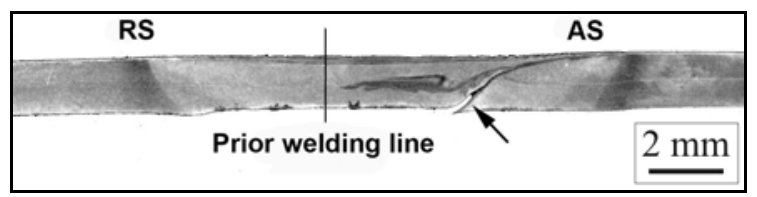

Fig. 13. The macrostructure of welded joint No. $2 \mathrm{~N}-400$ rev $\min ^{-1}, 100 \mathrm{~mm} \mathrm{~min}^{-1}$.

fabricated welded joint No. P5 was welded by parameters $400 \mathrm{rev}^{\mathrm{min}}{ }^{-1}, 200 \mathrm{~mm} \mathrm{~min}^{-1}$.

\subsection{Damage analysis of welded joints}

The crack detected by visual and RT test (Figs. 2, 3,6 ) localised on the advancing side of the weld is visible on weld macrostructure, Fig. 13. The mentioned inhomogeneity was localised on weld periphery and it forms some boundary between the zone which was stirred and the zone of base metal deformed in the thickness direction as can be seen at a metallographic cross section of the weld joint (Figs. 14, 16). The zone between the deformed and stirred section is very narrow what suggests on high strain gradients which are also connected with thermal gradients. This means that shear stresses were acting between the deformed zone and stirred zone by the welding tool simultaneously formed the mentioned failure mode. On the contrary, at the view on the retreating side of the weld (Figs. 15, 17), the transition between the stirred zone and base metal was wider and smooth without deformation bands on the base metal side. These differences are probably related to different ways of material flow on the advancing and retreating side of the weld.

The mentioned crack localised on the advancing side of the weld was opened and subjected to fracto- 


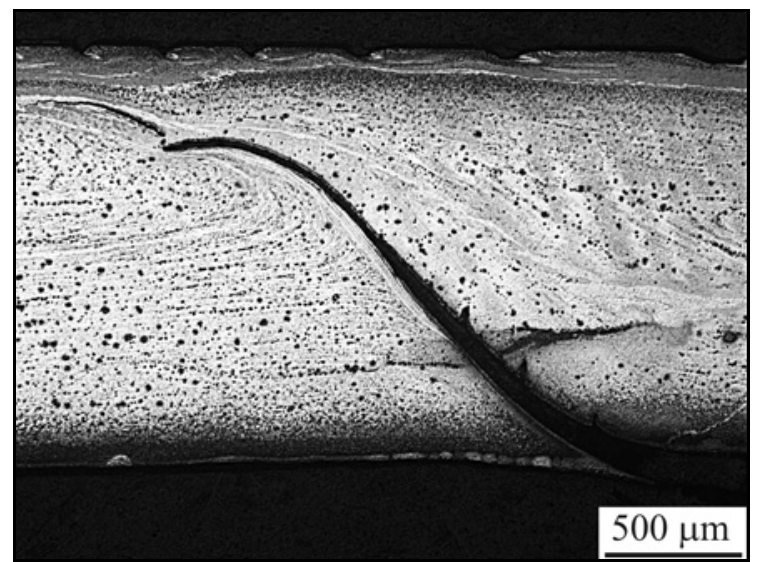

Fig. 14. The microstructure of sp.2N-advancing side - LePera etchant. Etching was inappropriate - the dark spots are artefacts, material deformation in thickness direction due to welding effect is visible.

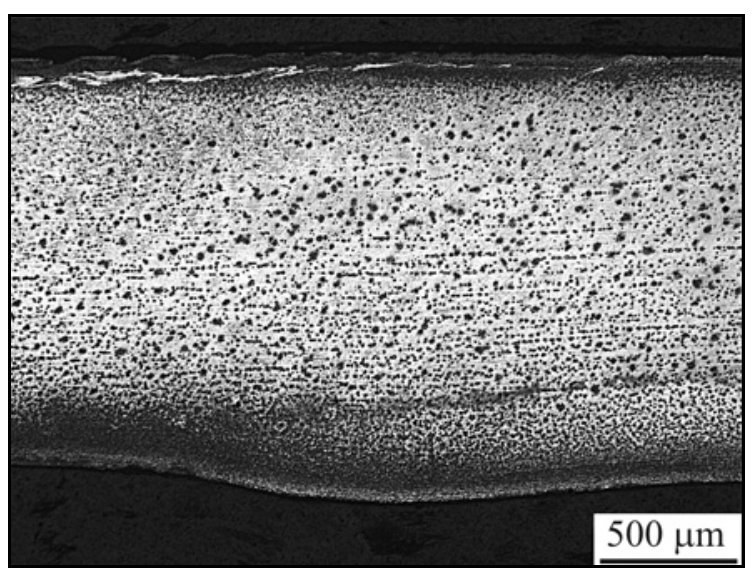

Fig. 15. The microstructure of sp.2N-retreating side - LePera etchant. Etching was inappropriate - the dark spots are artefacts, material deformation in thickness direction due to welding effect is invisible.

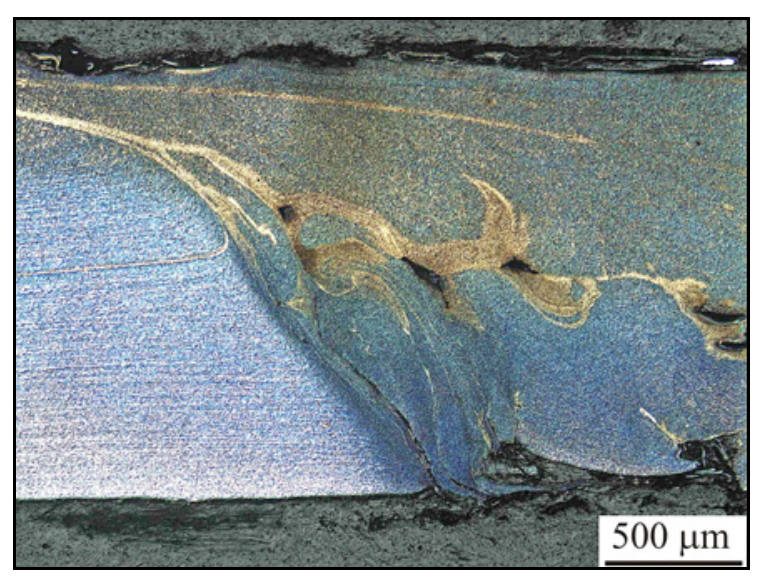

Fig. 16. The microstructure of sp.8N-advancing side - LePera etchant.

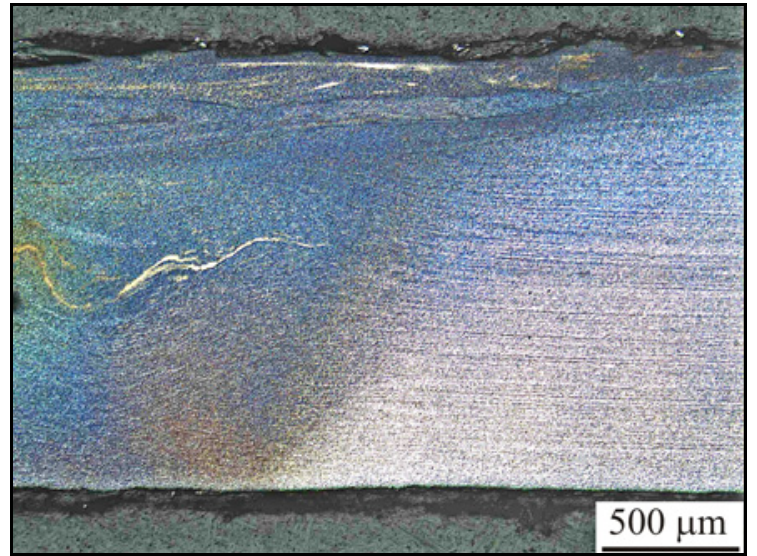

Fig. 17. The microstructure of sp.8N-retreating side - LePera etchant.

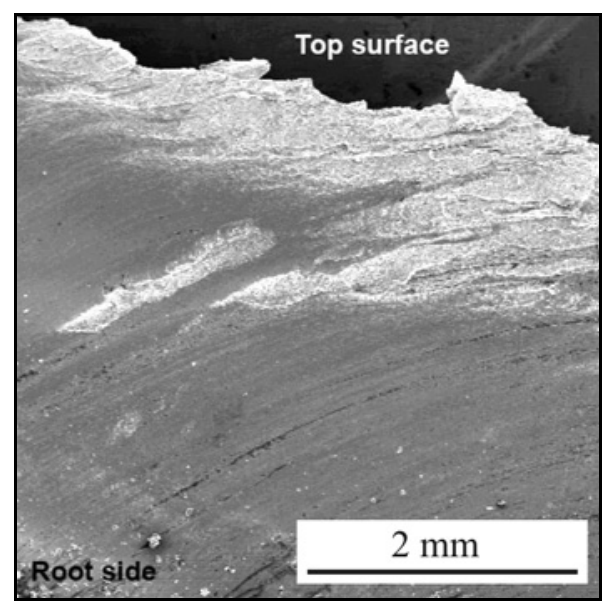

Fig. 18. Overall view on fractured surface propagation in the material thickness direction on advancing side of the weld.

graphic analysis. From an overall view of a fractured surface (Fig. 18), it is obvious that the surface is prevailingly smooth without indication of a metallurgical bond. Metallurgical diffusion bond was formed just in the upper layer of the weld, close to the outer surface (Fig. 19). These findings clearly prove that observed cracks are a mode of a cold weld formed in the moment of weld formation. As shown by the results of RT test and macrostructural analysis, the initial welding line is metallurgically bonded.

\subsection{Microstructural analysis}

Besides the failure analysis, also the microstructure of specimen No. $2\left(100 \mathrm{~mm} \mathrm{~min}^{-1}\right)$ was documented demonstratively.

The microstructure of base metal is shown in Fig. 20 after etching in $4 \%$ Nital and in Fig. 21 after etching in LePera etchant. This comparison 


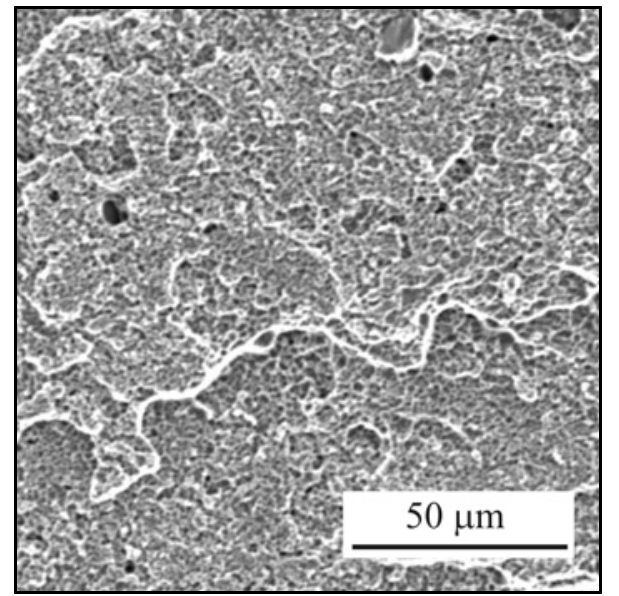

Fig. 19. Fracture morphology in the upper part of weld in final rupture zone.

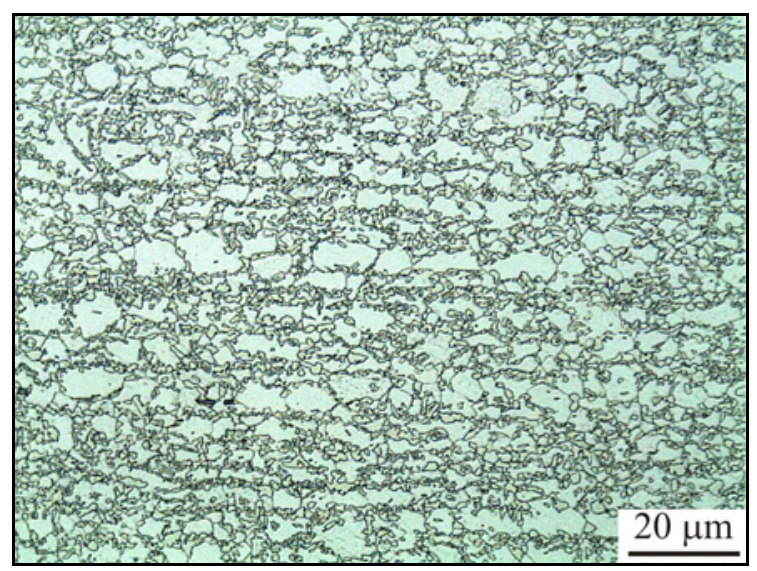

Fig. 20. The microstructure of base metal of TRIP 700 steel developed by $4 \%$ Nital etchant.

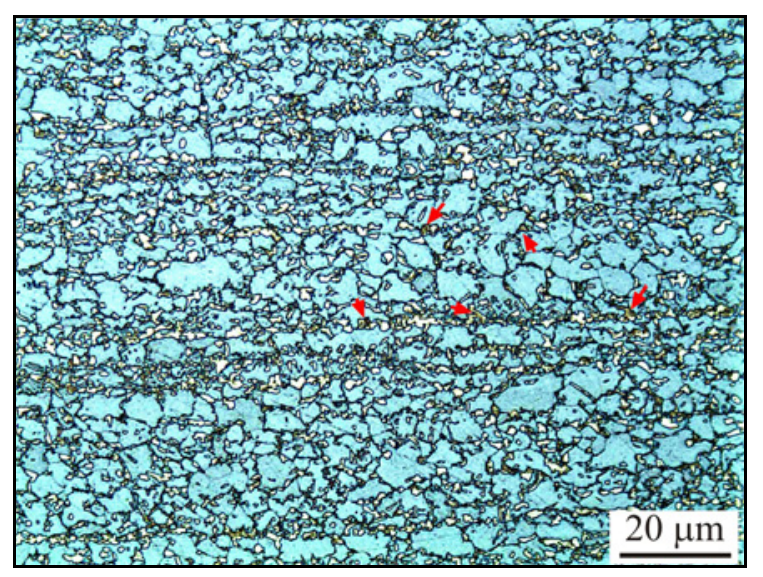

Fig. 21. The microstructure of base metal of TRIP 700 steel developed by LePera etchant, red arrows show the morphology of martensite/bainite phase.

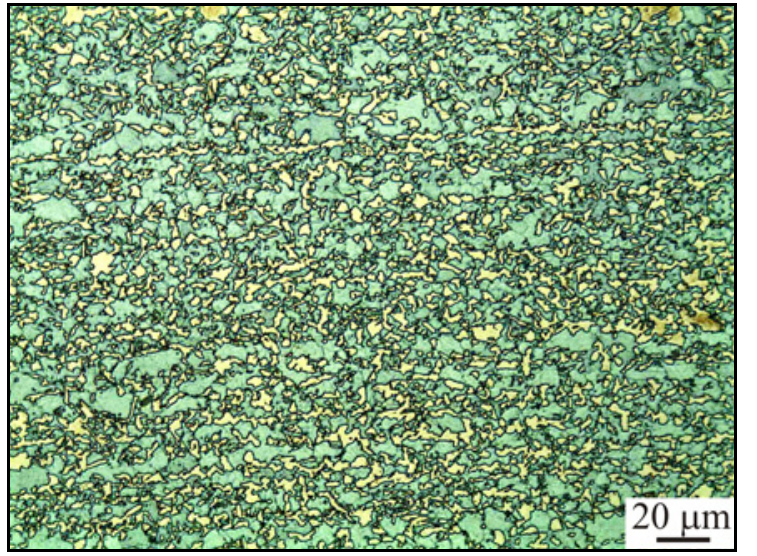

Fig. 22. The microstructure of sp.2 in CHAZ, advancing side of the weld.

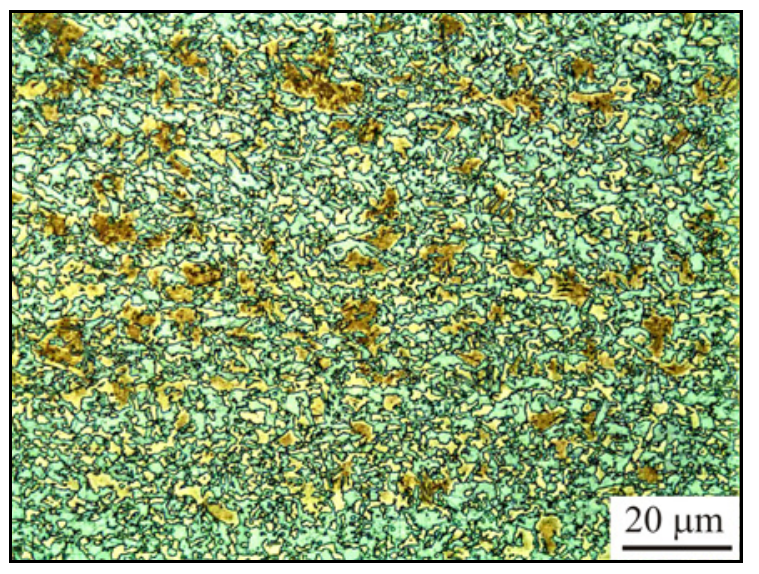

Fig. 23. The microstructure of $\mathrm{sp} .2$ in the range above A3, advancing side of the weld.

has shown that the resolution of structural components is clearer on microstructure developed by LePera etchant. The microstructure is in the majority composed of ferrite (blue grains) and in the minority of residual austenite (fine grains with white colouring) and martensite/bainite (fine grains brown-yellow colouring marked with red arrows, Fig. 21).

The proportion of mentioned structural components in a direction towards the weld varies. The proportion of martensitic/bainitic microstructure increases. The microstructure of inter-critical HAZ is shown in Fig. 22. Microstructure heated above A3 is shown in Fig. 23. Figure 24 represents the transition to weld, where also an analysed crack may be seen. Observations of the microstructure are in agreement with the measured hardness values (Fig. 26).

\subsection{Hardness measurements}

Hardness measurements were performed on metal- 


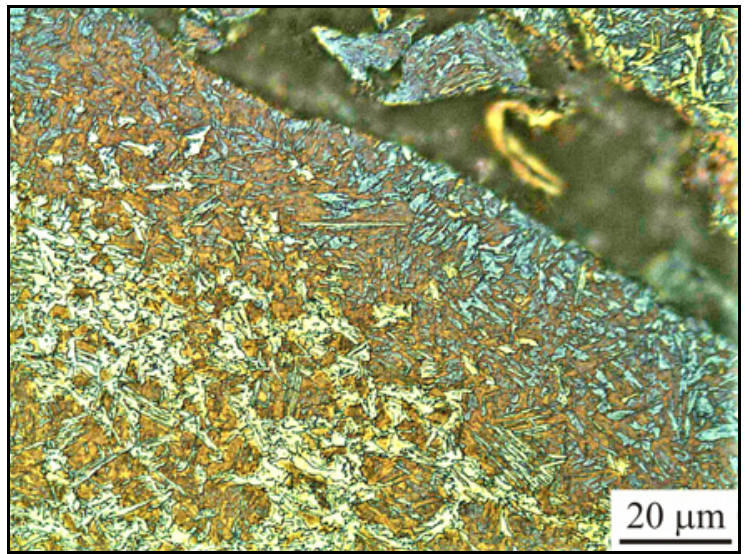

Fig. 24. Microstructure in transition to weld.

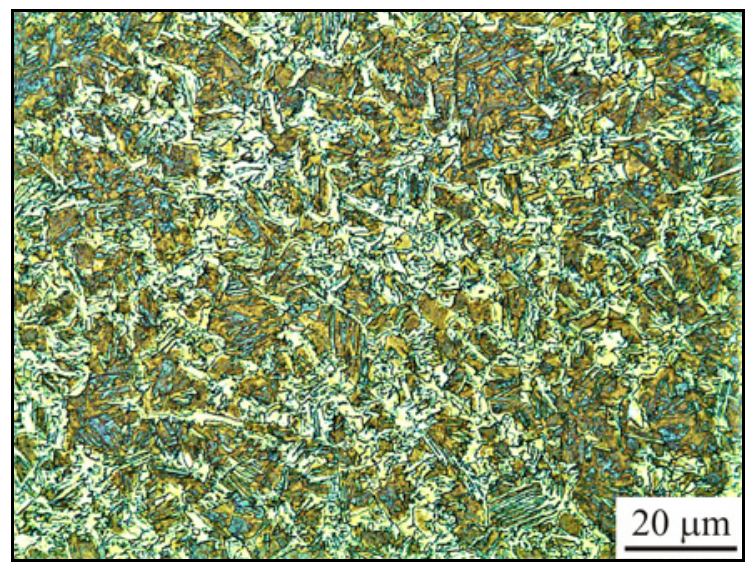

Fig. 25. Microstructure in weld centre.

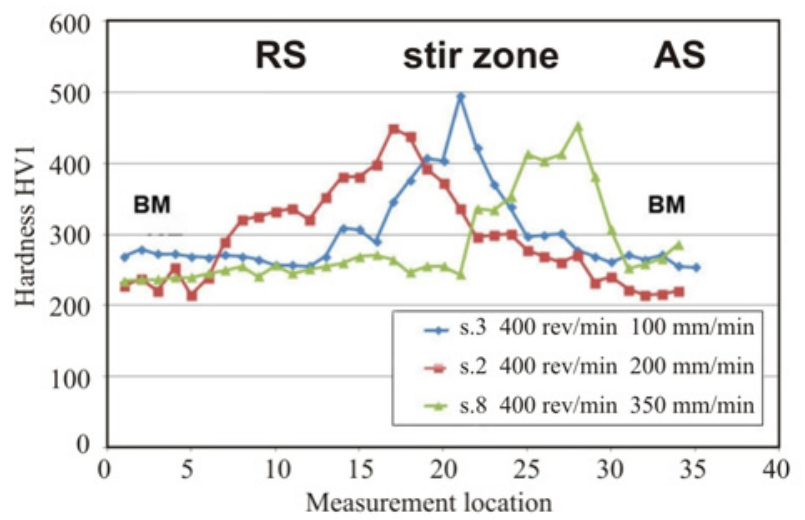

Fig. 26. The results of HV1 hardness measurement on the tested welded joints.

lographic cross sections from welded joints. Hardness was measured on one line approximately in the welded material centre. The following can be concluded from the hardness measurement (Fig. 14):
The hardness of base metal varies within the level from about 220 to $250 \mathrm{HV} 1$. The hardness gradually grows from the retreating side and its maximum is reached on the advancing side at the level above 400 HV1. Subsequently, hardness rapidly falls down to the level of base metal.

Such a course was recorded on all measured specimens. Mutual comparison of hardness profiles on specimens 2, 3, 8 has shown that the weld zone together with the HAZ is narrowing down in dependence on increasing welding speed, what was also expected, since the heat input was decreasing.

Moreover, the softened section in the heat affected zone was not observed in the hardness profile.

\section{Discussion and proposal of new experiments}

Based on the obtained results following suggestions can be mentioned. Due to shear stresses caused by the effect of deformation and thermal gradients, cold crack initiated from the lower surface on the advancing side in the zone between the deformed and stirred section. The cold cracks were present in each specimen, i. e. regardless the welding parameters used. The aim of supposed new experiments was thus to reduce the mentioned gradients. Since at the change in welding speed no significant change concerning the defect reduction was observed, our assumption was oriented to the change in welding tool geometry. This change will actually concern increased pin diameter of the welding tool, which was initially $\varnothing 5 \mathrm{~mm}$, to $\varnothing 6 \mathrm{~mm}$. By this modification, the contact area of the pin will be enlarged, resulting in the fact that the friction effect in the lower, coldest layers of the weld will be increased. In addition, also the difference between the shoulder and pin diameter will be reduced. This means that the forging effect of the shoulder which is forcing the material to rotate in thickness direction will also be reduced. The forging force from the shoulder is the source of shear stresses between the deformed and stirred zone while that force will be then lower owing to enlarged pin diameter.

\subsection{Suggestion of new experiments}

Parameters of welding with the new tool were selected similarly as in the previous experiments (Table 3).

Radiograms of the new welds are shown in Figs. 27, 28. Regarding the visual inspection and RT test the weld No. 16 was acceptable. The locally linear indication was observed in the weld No. 17. The mentioned welds were subjected to mechanical tests. Detailed metallographic analysis of the mentioned welds is not the object of this paper. The results of mechanical tests are shown in Table 4. 
Ta ble 3. Welding parameters used in experiments with the new-designed tool geometry

\begin{tabular}{cccc}
\hline Weld designation & Tilt $\left({ }^{\circ}\right)$ & Revolution speed $\left(\right.$ rev $\left.\min ^{-1}\right)$ & Welding speed $\left(\mathrm{mm} \mathrm{min}^{-1}\right)$ \\
\hline $16 \mathrm{~N}$ & 3 & 400 & 100 \\
$17 \mathrm{~N}$ & 3 & 400 & 150 \\
\hline
\end{tabular}

Table 4. Mechanical properties of welded joints No. 16 and 17

\begin{tabular}{|c|c|c|c|c|c|}
\hline Des. of spec. for tensile tests & Welding & arameters & $R_{\mathrm{m}}(\mathrm{MPa})$ & $R_{\mathrm{m}}(\mathrm{MPa}) \mathrm{ZM}$ & Fracture location \\
\hline $\begin{array}{l}16 \mathrm{~A} \\
16 \mathrm{~B}\end{array}$ & $400 \mathrm{rev} \min ^{-1}$ & $100 \mathrm{~mm} \mathrm{~min}^{-1}$ & $\begin{array}{l}761 \\
762\end{array}$ & \multirow{2}{*}{710} & $\begin{array}{l}\text { Fracture in } \mathrm{BM} \\
\text { Fracture in } \mathrm{BM}\end{array}$ \\
\hline $\begin{array}{l}17 \mathrm{~A} \\
17 \mathrm{~B}\end{array}$ & $400 \mathrm{rev}_{\min ^{-1}}$ & $150 \mathrm{~mm} \mathrm{~min}^{-1}$ & $\begin{array}{l}538 \\
654\end{array}$ & & $\begin{array}{l}\text { Fracture in WM } \\
\text { Fracture in WM }\end{array}$ \\
\hline
\end{tabular}

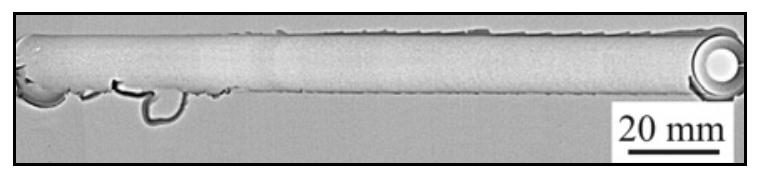

Fig. 27. Welded joint No. 16 welded with the newdesigned tool and the welding parameters: $400 \mathrm{rev} \mathrm{min}^{-1}$, $100 \mathrm{~mm} \mathrm{~min}^{-1}$.

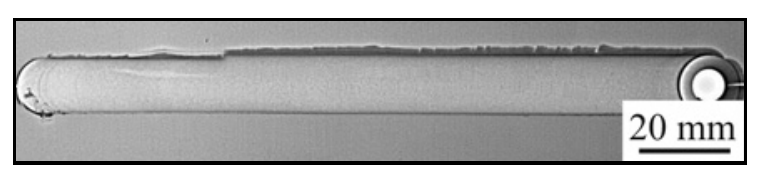

Fig. 28. Welded joint No. 17 welded with the newdesigned tool and the welding parameters: $400 \mathrm{rev} \mathrm{min}^{-1}$, $150 \mathrm{~mm} \mathrm{~min}^{-1}$.

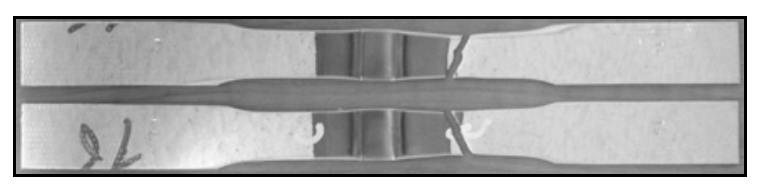

Fig. 29. Welded joint No. 16 - flat tensile specimens after the uniaxial tensile test.

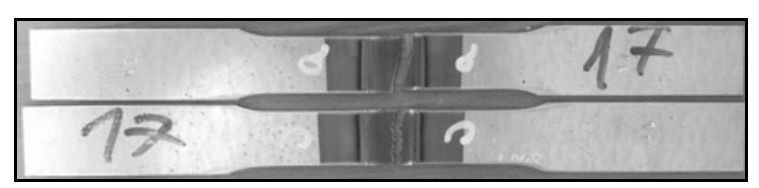

Fig. 30. Welded joint No. 17 - flat tensile specimens after the uniaxial tensile test.

Overall view on the ruptured flat tensile specimens after the uniaxial tensile test is shown in Figs. 29, 30.

The results of the mechanical test have shown that the tensile specimens No. $16 \mathrm{~A}, \mathrm{~B}$ were ruptured in the base metal. Therefore, their strength achieved the strength of the base metal. In the case of test specimen No. 17, they ruptured in the weld. The weld strength was at the level of 76 to $92 \%$ of base metal strength. In the case of test specimen $17 \mathrm{~b}$ the fracture location partially corresponds with the location of mentioned defects. In the case of test piece 17 a rupture has occurred in weld centre in the location of the initial welding line. Rupture of test piece initiated from the lower side of the weld, probably from the root with the lack of fusion. This defective root is the result of the short length of the tool pin at the given welding speed. At higher welding speeds this parameter must be optimised, i. e. it is necessary to prolong the pin length.

\section{Conclusion}

Friction stir welding of hot-dip galvanised Trip 700 steel with thickness $1.56 \mathrm{~mm}$ caused peeling of the zinc in the form of metal shavings with high density at the weld surface. $\mathrm{Zn}$ layer is a barrier against stirring of welded materials simultaneously lead to visually visible defect formation at advancing side of weld periphery. Microstructural heterogeneity, maximum hardness peak 450-500 HV1 and steep increase to maximum value was measured in this location in comparison with rest of the stir zone.

Furthermore, surface Zn coating caused welding tool destruction by liquid metal embrittlement mechanism.

The achieved results have shown that a slight modification in tool geometry, $1 \mathrm{~mm}$ increase in pin diameter, exerts a significant effect on the homogeneity and quality of fabricated welds.

\section{Acknowledgement}

This publication is the result of the project implemen- 
tation: Research of the friction stir welding (FSW) application as an alternative to melting welding methods, ITMS: 26240220031, supported by the Research \& Development Operational Programme funded by the ERDF.

\section{References}

[1] Ghosh, M., Kumar, K., Mishra, R. S.: Material Sci. Eng. A, 528, 2011, p. 8111. doi:10.1016/j.msea.20_11.06.087
[2] Lomholt, T. C.: Microstructure Evolution during Friction Stir Spot Welding of TRIP steel. [Ph.D. Thesis]. Kongens Lyngby, Technical University of Denmark 2011. http://orbit.dtu.dk/ws/files/51979600/Trine_Nybo_ Lomholt.pdf

[3] Yamazaki, K., Sato, K., Tokunaga, Y.: Welding International, 14, 2000, p. 533. doi:10.1080/09507110009549225

[4] Hovanski, Y., Santella, M. L., Granta, G. J.: Scripta Mater., 57, 2007, p. 873.

doi:10.1016/j.scriptamat.2007.06.060 